is that the prenatal cases were drawn mostly from families of low income. With regard to the second, he admits that women of unusually low intelligence would probably not seek or be interested in accepting the prenatal work; but, on the other hand, he had no reason to believe that the mothers who received the prenatal care represented any higher order of intelligence than the average of their locality. Dr. Davis further gives detailed tables regarding the causes of death in the fatal cases, etc., which may be usefully studied; but the outstanding and impressive result is the demonstration that prenatal care does diminish both the still-birth rate and infantile mortality, and that it does not fail to have a good restrictive effect upon what may be called the neonatal death-rate, which is the most serious part of the infantile rate. One was prepared to know that prematernity work benefited the pregnant women themselves; but this striking exhibition of its good effect upon antenatal and neonatal welfare could hardly have been confidently expected.

J. W. B.

\title{
INFECTIOUS DISEASES.
}

UNDER THE CHARGE OF

CLAUDE B. KER, M.D.

\section{Treatuent of Enteric Fever with Colloidal Gold.}

Salonon (La Presse Médicale, 5th October 1916) has an interesting account of the treatment of enteric fever by this method. The use of colloidal metals in infective conditions appears to have been relatively common in France since 1902, when Netter drew attention to its possibilities. It, nevertheless, has not, in the opinion of Salomon, won the popularity which it deserves, and he considers that this is due to the unpleasant results which frequently follow the intravenous method of injection, which is that generally practised. Enteric patients, moreover, appear to be less tolerant of the drug, when administered in this manner, than are persons suffering from other diseases. In 1914 Letulle and Mage reported excellent results in enteric fever, and the difficulty of employing balneation systematically in the military hospitals no doubt helped to introduce a method of treatment which can be easily carried out.

The bad results which are liable to follow the introduction of colloidal gold into a vein, while perhaps especially severe in enteric fever cases, occur equally in other diseases subjected to the same method of treatment. The injection is followed by violent rigors and symptoms resembling a malarial attack. Vomiting and involuntary evacuations sometimes occur. Cyanosis, dyspnœea, and a rapid thready pulse often cause great anxiety, and must be promptly treated with 
hot drinks and cardiac stimulants. After this cold shivering stage the temperature rises to high levels, which, of themselves, must be regarded as dangerous. Profuse sweating with a fall of temperature follows, and in favourable cases the pyrexia subsides altogether, though this appears to occur seldom after the first injection.

Salomon is convinced of the efficacy of this treatment which he employed in 77 cases, and would have continued to employ, had he not been impressed by the risk of fatal collapse. The dose given did not affect the result. Some patients tolerated 2 c.c. fairly well, others were seriously upset by doses of 1 c.c. or even $\frac{1}{2}$ c.c., and it seems probable individual idiosyncrasy plays some part. The moral is therefore, to try and get equally good therapeutic results by another method of administration than the intravenous one. As Salomon had observed that the first dose usually caused the greatest disturbance, he endeavoured to accustom the patient to the drug by preliminary subcutaneous injections, doses of 10 to 12 c.c. being given by this route. Slight reactions of temperature sometimes followed the injections and the general results, though fairly favourable in 44 cases, appeared doubtful. The subcutaneous injections, moreover, were extremely painful. Finally, then, Salomon tried intramuscular injections, and found them free from the disadvantages of the intravenous and more effective than the subcutaneous ones. They cause no pain. There is sometimes a short attack of shivering, and usually a reactionary rise of temperature. By next day the temperature of the patient has been appreciably reduced and the general condition improved. Occasionally there is very free discharge of urine, and the temperature falls to normal and remains there. More frequently further injections are required, being indicated when the temperature begins once more to rise, usually at intervals of two days. The dose employed for intramuscular injection is from 2 to 4 c.c., and, in Salomon's view, the action, if a little slower, is as reliable as when the drug is administered intravenously.

Jouve-Balmelle (Le Progrès Médical, 5th September 1916) has also made use of this method of treatment with success, having, like Salomon, hesitated to employ the intravenous route on account of the accidents produced. As a general rule, 2 c.c. of electraurol were injected into the muscles daily, and, if we are to judge by the temperature charts which illustrate the two articles, with more definite and obvious results than those that followed the more sparing and cautious administration of the remedy by Salomon, whose charts are somewhat unconvincing. Jouve-Balmelle claims that the treatment is followed by progressive lowering of temperature, which persists if the injections are continued and ceases if they are suspended.

I am unaware whether colloidal gold has been used in the treatment of enteric fever in this country. The intramuscular method should certainly make its employment more simple, and a study of Jouve- 
Balmelle's temperature charts suggests that the drug does exercise some influence on the course of the fever. The somewhat abrupt termination of some of the cases reported by Salomon, on the other hand, might be explained by the fact that the patients had been vaccinated against the fever and were therefore perhaps likely to have an abortive attack in any case. In others, again, the infection was a paratyphoid one, and to some extent, therefore, less severe. On the whole the treatment appears to do no harm, and a trial of it might be well worth while. Both writers used other therapeutic measures concurrently with the injections, Salomon's cases in particular being treated with the continuous application of ice to the abdomen.

\section{The Influence of Uremia in Enteric Fever.}

Jouve-Balmelle (loc. cit.) raises many points of interest in the paper just quoted, but devotes his main attention to the question of albuminuria in enteric fever, and its results. In 600 cases he found albumin absent only in fifteen, an experience which must surely be very unusual. He admits that the albumin in two-thirds of the cases was only present in very small quantity, though sufficient in his opinion to justify the absolute restriction of the patient to a milk diet. But in one-third of the cases the implication of the kidney was much more definite, and marked diminution in the amount of urine, large quantities of albumin, and occasionally suppression of urine were observed relatively frequently.

Of the patients treated by Jouve-Balmelle 180 were of the "ataxoadynamic" type, that is to say, they were in what we should describe as the "typhoid state." Nervous complications were common, and twenty cases suffered from meningism, some even showing stiffness of the neck and Kernig's sign. Only two, however, had a real meningitis, the spinal fluid in the remainder being quite normal. As some of the worst cases also suffered from renal trouble, it appeared to JouveBalmelle that uræmia possibly was the real cause of the "typhoid state." He considers that the usual symptoms of uræmia are very similar to those of severe typhoid fever with nervous symptoms. He was led by this observation to examine the blood quantitatively for urea, and his investigation resulted in the finding that, while the ordinary cases of enteric fever examined showed no augmentation of the amount of urea in the blood, the ataxo-adynamic cases gave a more or less marked increase of the normal figure, or, in other words, had definitely uræmia. Moreover, the amount of urea in the blood was, as it were, parallel to the condition of the patient, increasing and diminishing synchronously with the exacerbation or cessation of the nervous symptoms. JouveBalmelle, therefore, concludes that " the ataxo-adynamic condition does not constitute a form of enteric fever due to the action of the bacillus 
or its toxins on the nerve centres. The nervous symptoms of the fever are associated with a complication-uræmia-the symptomatology of which they reproduce, and which itself depends on the primary complication-typhoid nephritis." The importance of this theory is obviously its bearing upon therapeutics. The application of treatment suitable for uræmia, a rigid milk diet, and local and general bleedings gave Jouve-Balmelle excellent results. Whereas 23 per cent. of 106 cases with nervous manifestations terminated fatally in the period previous to this uræmic treatment being applied, after its inauguration only 12 per cent. of seventy-four ataxo-adynamic patients died. These results are certainly very striking; but meningism undoubtedly occurs in patients who show no albuminuria, and albumin is by no means an invariable symptom in the typhoid state. In our Edinburgh cases albuminuria is in fact very unusual. Nevertheless the estimation of the amount of urea in the blood of cases of the type under discussion might be practised with advantage, even if we are reluctant to admit that urea is responsible for symptoms which we have long confidently attributed to the action of the toxins of the typhoid bacillus. The patients treated by the French observer were military ones. Is it possible that some at least of them were also the victims of the nephritis which appears to have been so common in the trenches?

\section{Notification of the Minor Infectious Diseases.}

Williams (Albany Medical Annals, August 1916) gives reasons why it is desirable that such apparently trivial ailments as chicken-pox, mumps, and rubella should be made notifiable. An inquiry was made as to the opinion of eighteen leading public health experts and clinicians, and, as a result, it was decided to require the notification of the diseases in question for the following reasons :- In the first place, without notification any attempt to control or abolish these infections would be futile. Chicken-pox is not infrequently confused with smallpox and is a very contagious disease, and is, in addition, liable to be dangerous in itself. Rubella should merely be notifiable, and its diagnosis should be confirmed by experts in order to prevent confusion with scarlet fever. Mumps may be a more serious disease than is usually supposed, and for this reason should be reported.

The rules laid down for isolation and disinfection are not without interest. Chicken-pox cases are isolated for at least twelve days or until the crusts have fallen and the scars completely healed. The medical officer may order disinfection in cases in which he thinks it desirable; otherwise it is apparently not insisted on. Mumps requires isolation for a period of not less than two weeks or one week after the disappearance of swelling. Neither isolation nor terminal disinfection is required in the case of rubella. 
While it must, of course, be admitted that notification of all infectious diseases is theoretically desirable, it is doubtful if these rules will be imitated in this country, and it is certain that the advantages would not justify the expense. The greater prevalence of smallpox in the United States gives a valid reason for the notification of chicken-pox in that country, but our own custom of notifying it during smallpox epidemics is probably sufficient for the purpose, though accidents, due to the more severe disease being regarded as chicken-pox, do undoubtedly happen. The risks of mumps seem to be somewhat exaggerated, and as their incidence is in the early stage of the disease, it is difficult to see how notification would obviate them. We may well doubt if expert supervision of cases notified as rubella would commend itself to the general practitioners of this country. Our Edinburgh experience is that it is much more common for rubella to be labelled scarlet fever than it is for the reverse to take place. A good point, however, in the American rules is the abolition of isolation for this very trivial condition.

\section{THERAPEUTICS.}

UNDER THE CHARGE OF

JOHN EASON, M.D.

\section{The Action of Digitalis in Pneumonia.}

Fron time to time the discussion is renewed as to whether the use of digitalis in pneumonia is advantageous. A decision has been difficult, because the difference between action as such and beneficial action has not been sharply drawn. One or two eminent authorities have stated that, when given by the mouth, digitalis is of no practical value, if it has any action at all in pneumonia. A. E. Cohn and Ross A. Jamieson have recently made some valuable observations on the subject as the result of their investigations in the Hospital of the Rockefeller Institute for Medical Research (Journ. Exper. Med., No. 1, vol. xxv. p. 65). They show that action on the heart by digitalis takes place in pneumonia, and also that its action under certain circumstances is beneficial. The number of cases of pneumonia on which the observations were based was 105 .

Digitalis was given to 49 patients ; another 56 cases of pneumonia received no digitalis and served as controls. The drug was usually given by the mouth in the form of tablets of digipuratum, each tablet containing the equivalent of $0 \cdot 1 \mathrm{grm}$. of the powdered leaves. The daily dose was usually $0.4 \mathrm{grm}$. Electrocardiograms were made of all the patients. In the patients to whom digitalis was administered the curves were made frequently - usually once, or oftener, each day. As criteria for judging the action of digitalis the effect upon the length 